Article

\title{
Enhancement of the Oil Absorption Capacity of Poly(Lactic Acid) Nano Porous Fibrous Membranes Derived via a Facile Electrospinning Method
}

\author{
Jun-Wei Liang, Gajula Prasad, Shi-Cai Wang, Jia-Lin Wu and Sheng-Guo Lu *(D) \\ Guangdong Provincial Research Center on Smart Materials and Energy Conversion Devices, \\ Guangdong Provincial Key Laboratory of the Functional Soft Condensed Matter, School of Materials and Energy, \\ Guangdong University of Technology, Guangzhou 510006, China; 11075351307@163.com (J.-W.L.); \\ prasad.th7@gmail.com (G.P.); S136544353@163.com (S.-C.W.); wuxiaoxiao_19827@163.com (J.-L.W.) \\ * Correspondence: sglu@gdut.edu.cn
}

Received: 25 January 2019; Accepted: 5 March 2019; Published: 12 March 2019

check for updates

Featured Application: The porous fibrous membranes could be used for environmental protections, e.g., spilled oil absorption.

\begin{abstract}
Oil spilling has been a serious problem in the world for a long time, which can bring toxic substances to marine life. A large number of researchers around the world have introduced many measures to address this problem. One of the effective methods to remove oil from the oil/water mixture is to absorb oil from the mixture. Here, we prepared porous poly(lactic acid) (PLA) membranes using the electrospinning approach with different sized syringe needles, and used these membranes to absorb oil from the top of the water. It was found that the diameter of the needle has a big impact on the size and structure of the pores on the PLA fibers. The oil absorption capacity of membranes increases with a decreasing needle diameter due to the increased pore volume and specific surface area. The highest absorption capacity reached was $42.38 \mathrm{~g} / \mathrm{g}$ for vacuum pump oil, $28.17 \mathrm{~g} / \mathrm{g}$ for peanut oil, and $6.74 \mathrm{~g} / \mathrm{g}$ for diesel oil.
\end{abstract}

Keywords: electrospinning; pores; oil absorption capacity

\section{Introduction}

Much attention has been paid to oil spilling over many decades due to the reason that it might bring toxic matters to marine life. As a result, this harmful matter will be transferred into human bodies through the food chain [1,2]. With an increase in people's awareness of environmental protection, researchers around the world have become devoted to decontaminating the ocean pollution caused by oil spills. Currently, adsorbent materials, such as fabric-based materials [3,4], sponge and foam-based materials [5,6], and some inorganic materials like carbon-based aerogels [7], have been widely used as potential solutions to ocean pollution. These materials have high oil sorption capacity, low reaction with the water/oil and low cost. In addition, hydrophobic organic materials play an important role in separating the oil and water. However, most of the hydrophobic materials, e.g., polystyrene (PS) [8-11] and polydimethylsiloxane [12,13], are difficult to degrade naturally (contrary to some degradable polymers used in medical applications, polyesters, polyesteramides, poly(ortho ester)s, polyurethanes, polyanhydrides, cyanoacrylates, and hydrogels, e.g., based on poly(ethylene glycol)) [14]) and form secondary pollution, despite their high oil-sorption capacity.

Poly(lactic acid) (PLA) is a biodegradable organic material which has been widely used. Due to their high specific surface area, PLA fibers have been used as the scaffold for drug delivery and tissue engineering [15]. Electrospinning is a high-efficiency, simple, and low-cost process for the 
preparation of various nanofibers. Electrospinning-derived PLA fiber membranes demonstrate high hydrophobicity [16] because their superficial area increases. Water cannot penetrate the PLA membranes and only stays on the surface of membranes. In addition, blending the PLA membrane with another material can change the morphology of the fibers. Xu et al. managed to blend the PLA and chitosan to make electrospun fibers. They found that with an increase in chitosan content, the diameter of the mixed fibers decreased [17]. Lu et al. tried to blend the PLA with poly(ecaprolactone) to make electrospun fibers. They observed that with the increase of poly (ecaprolactone) content, the diameter of fibers decreased [18]. These investigations focused on blending other materials with PLA to change the morphology of the PLA fibers, which can affect the specific surface areas and surface roughness, while they were less focused on the effect on the pores' formation via varying the needle sizes and water permeability of electrospun membranes and related hydrophobic separation of oil/water suspension. Moreover, the degradability of mixed materials might not be as efficient as pure PLA.

In this work, the pure PLA fiber sorbents were fabricated using an electrospinning process with different needle sizes. The effect of needle size on the porous morphologies of fibers and the oil absorption capacities for pump oil, peanut oil, and diesel oil were investigated and discussed.

\section{Materials and Methods}

PLA 6052D ( $\rho=1.24 \mathrm{~g} / \mathrm{cm}^{3}$, the glass transition temperature is at about $58{ }^{\circ} \mathrm{C}$, NatureWorks, Nebraska, USA), dichloromethane (DCM), and dimethyl formamide (DMF) (Tianjin Da Mao Chemical Reagent, Tianjin, China) were used as the fiber material and two solvents, respectively. All reagents are utilized without further purification. A plastic syringe (Foshan Lepton Precision Measurement \& Control Technology, Foshan, Guangdong, China) with a stainless steel needle of different inner diameters $(0.50,0.67,0.86,1.26$, and $1.60 \mathrm{~mm}$ respectively) was employed as the electrospinning equipment. The samples were named F1, F2, F3, F4, and F5, respectively.

An amount of PLA (10 wt.\%) was dissolved in a mixture of DCM and DMF (9:1 weight ratio) at room temperature with stirring for $2 \mathrm{~h}$ to form the precursor solution. The solution was then put into a $20 \mathrm{~mL}$ plastic syringe. In order to form the PLA fibers with different diameters, metallic needles with inner diameters of $0.50,0.67,0.86,1.26$, and $1.60 \mathrm{~mm}$ were used. The high voltage applied between the needle tip and the collector was set to $18 \mathrm{kV}$, and the distance between them was $15 \mathrm{~cm}$. The flow rate was fixed at $0.5 \mathrm{~mL} / \mathrm{h}$. A temperature of $25 \pm 2{ }^{\circ} \mathrm{C}$ and Relative humidity of $65 \pm 5 \%$ were used during the electrospinning process. Afterwards, the porous fibers were annealed at $70^{\circ} \mathrm{C}$ for over $12 \mathrm{~h}$.

To analyze the maximum oil absorption capacity using the procured fiber membranes, $10 \mathrm{~g}$ vacuum pump oil (dyed a green color) was poured into a beaker which contained $80 \mathrm{~mL}$ of water. A quantity of $0.5 \mathrm{~g}$ of the fiber was placed on the surface of the oil which was on the top of water. After $10 \mathrm{~min}$, the wet absorbent was drained for $2 \mathrm{~min}$ until no residual oil droplets were left on the surface. Oil absorption capacities of all absorbents were determined by the following equation:

$$
\delta=\frac{\left[m_{f}-\left(m_{0}+m_{w}\right)\right]}{m_{0}}
$$

where $\delta$ is the absorption capacity $(\mathrm{g} / \mathrm{g}), m_{f}$ is the weight of the wet absorbent after $10 \mathrm{~min}$ of immersion, $m_{0}$ is the initial weight of the absorbent, and $m_{w}$ is the weight of adsorbed water (although the absorbent is placed in the up oil layer, practically, the water is usually absorbed at the same time. To exactly measure the absorbed oil and water weight, the porous fiber was imposed in pure water and pure oil respectively, and the absorbed weights were recorded). In pure oil medium without any water, $m_{w}$ is equal to zero. To explore the selectivity of different oils, the same fibrous membranes were put into different types of oil (vacuum pump oil, peanut oil, and diesel oil) for absorption and to test their individual absorption capacity.

The SEM images were taken using a scanning electron microscope (SEM, SU8220, Hitachi, Tokyo, Japan) and the diameters of fibers were measured using Image J software. Functional groups of the 
fibers were measured in absorbance mode by an Attenuated Total Reflection Flourier Transformed Infrared Spectrometer (ATR-FTIR, Nicolet IS50, Thermofisher, Massachusetts, USA). The wavenumber ranged from 400 to $4000 \mathrm{~cm}^{-1}$. The contact angle was measured using a contact-angle system (JC2000D2, Shanghai Zhongchen Digital Technology Co. Ltd. Shanghai, China) at $25^{\circ} \mathrm{C}$, and the specific surface areas of five samples were measured using a Surface Area and Porosimetry Analyzer (BET, V-Sorb 2008B, Gold APP Instrument Corporation, Beijing, China).

\section{Results and Discussion}

\subsection{Morphology}

Figure 1a-e show the images of the five samples. Fibers were randomly deposited on the aluminum foil, and the diameters of fibers were $1.50 \pm 0.21,1.47 \pm 0.23,1.42 \pm 0.32$, $1.30 \pm 0.38$, and $1.27 \pm 0.34 \mu \mathrm{m}$, respectively. All morphologies were measured using Image J software. The differences in fiber diameter were due to charge repulsion and the synergistic effect between the surface tension and the electric interaction. When a high voltage is applied, the charged droplets at the needle tip are not only subjected to surface tension, but also to charge repulsion caused by the electric field. When the charge repulsion on the droplet is larger than its surface tension, the droplet will form a jet. Then, a fiber is formed and eventually deposited on the collection plate (aluminum foil). Both the charge repulsion and the surface tension are related to the droplet's radius. Their relationship can be illustrated as follows. In addition, the pore volume was also observed to increase with the decreasing needle diameter, as shown in Figure 2.
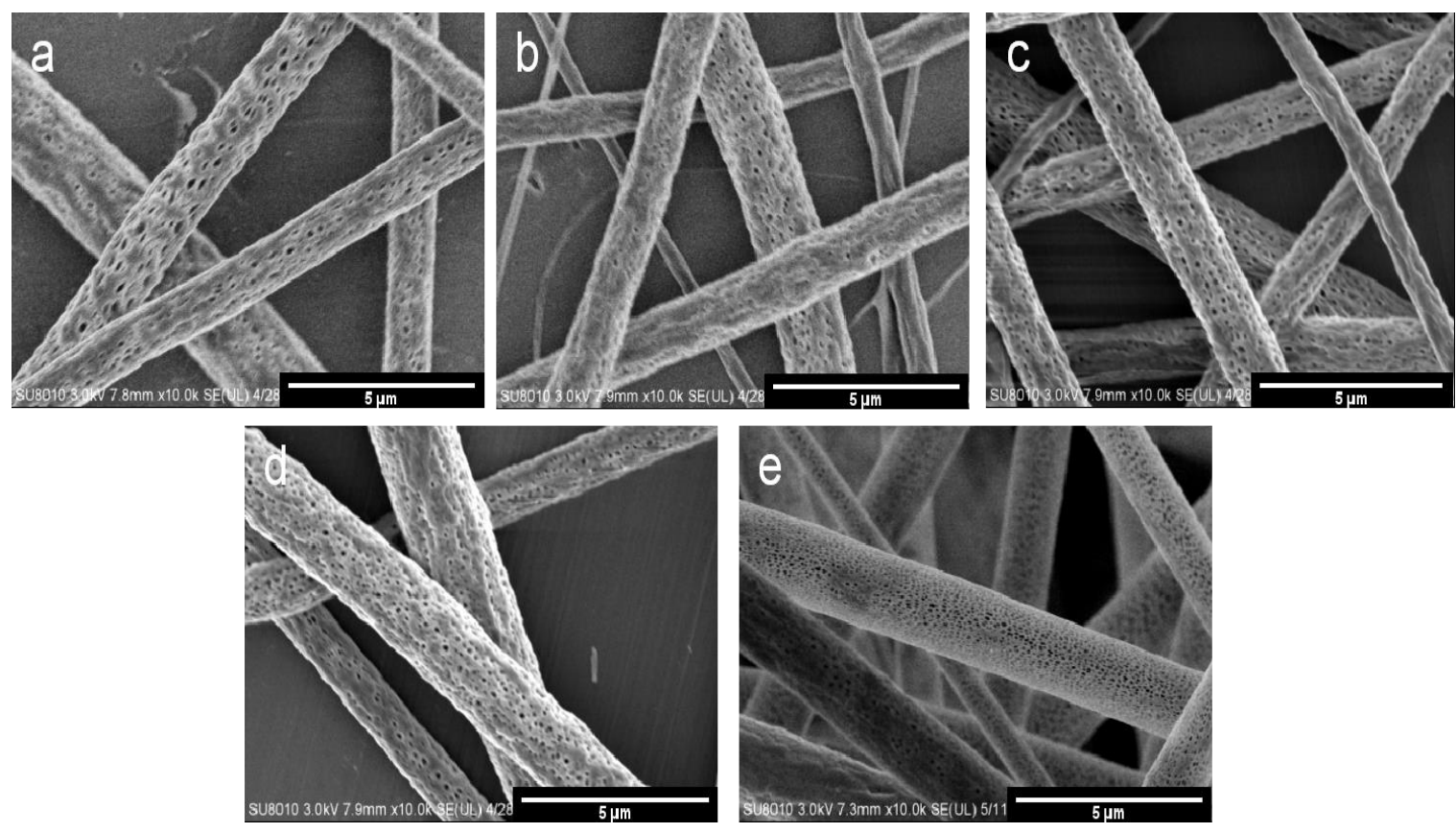

Figure 1. SEM (scanning electron microscope) images of different PLA porous fibers prepared using different needle diameters: (a) 14 G, (b) 16 G, (c) 18 G, (d) 19 G and (e) $21 \mathrm{G}$. (All images are $\times 10.0 \mathrm{k}$ ). 


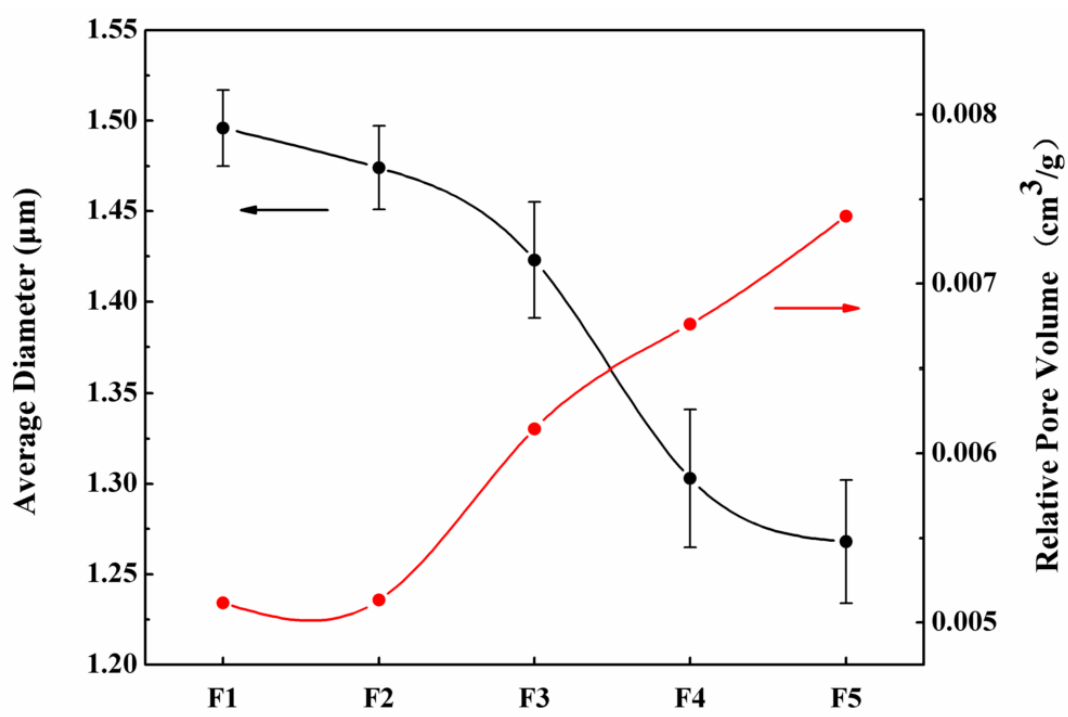

Figure 2. Average fiber diameters (black line) and relative pore volumes (red line) of porous fibers obtained using different needle diameters.

The electrostatic pressure on the $\operatorname{droplet}\left(P_{E}\right)$ is [19]

$$
P_{E}=\frac{\sigma^{2}}{2 \varepsilon}
$$

where $\sigma$ is the surface charge density of droplet and $\varepsilon$ is the dielectric constant in vacuum. The pressure of the droplet at the needle tip related to the droplet radius $\left(P_{C}\right)$ can be expressed as [19]

$$
P_{C}=\frac{2 \gamma}{R}
$$

where $\gamma$ is the surface tension of the droplet and $R$ is the radius of the droplet.

Above two pressures, the non-equilibrium is formed and can be written as [19]

$$
\Delta \mathrm{P}=P_{C}-P_{E}=\frac{2 \gamma}{R}-\frac{e^{2}}{32 \pi^{2} \varepsilon R^{4}} .
$$

Based on Equation (4), smaller droplets are easily subjected to electrostatic pressure. In other words, small droplets more easily form small diameter fibers after stretching in an electric field. It was found that the size of the droplet at the tip is associated with the inner diameter of needle, i.e., a smaller droplet radius is usually formed at the tip of the smaller diameter of the needle. A schematic diagram to illustrate the mechanism is shown in Figure 3. Wu et al. used PS to make fibers with different diameters of needles via the electrospinning technique, they also obtained fibers with different diameters [20,21].

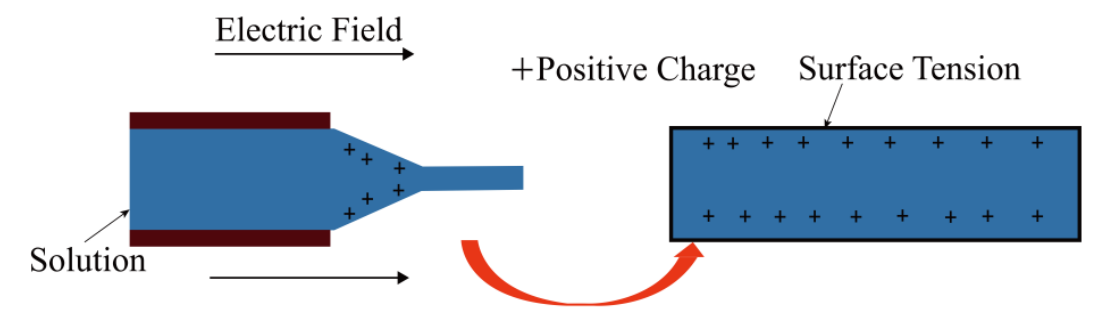

Figure 3. A schematic diagram of droplet stretching from the needle tip to the collection board in a high electric field. 
The pore size was also affected by the diameter of the needle. In fact, the formation of pores in the fiber is attributed to the solvent evaporation of small molecule solvent and the polymerization of the polymer PLA. When evaporation is stronger during polymerization in the course of the electrospinning process, pores are formed. When evaporation is weaker during polymerization, there will be no pores formed. For droplets with a larger size coming out from the larger sized needle, it is harder for the solvent to evaporate from the fiber; thus, the pores are smaller in size, while for droplets with smaller size coming out from the smaller sized needle, there is a larger specific surface area for the solvent to evaporate from the fiber; thus, the pores are larger in size. A schematic diagram is shown in Figure 4 to illustrate the mechanism of the formation of pores in fibers.

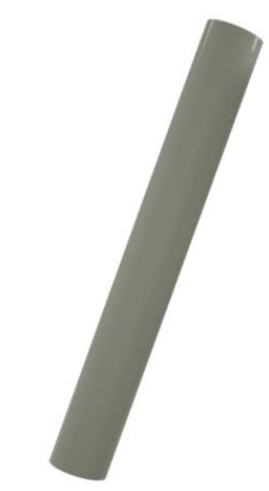

Smooth Fiber

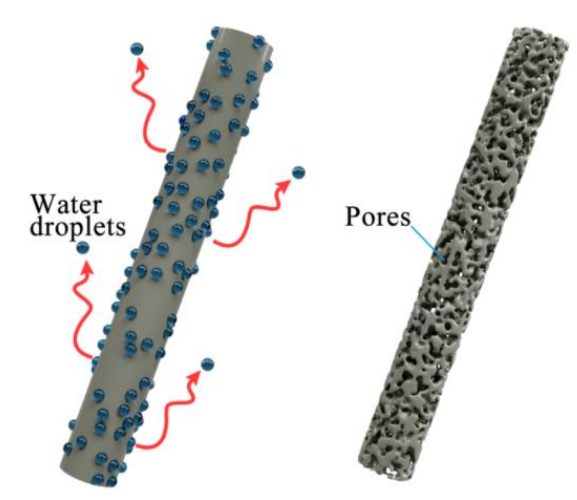

Porous Fiber

Figure 4. A schematic diagram of pores formed in fibers.

\subsection{Wettability}

Wettability is an important parameter for adsorption materials, which is generally characterized by the water contact angle (WCA). A water droplet of about $2 \mu \mathrm{L}$ was dropped on the surface of the sample to be measured. If the WCA is larger than $90^{\circ}$, as shown in Figure 5a, it means the sample is hydrophobic. In contrast, an oil droplet of about $2 \mu \mathrm{L}$ also dropped on the surface of the sample, as shown in Figure 5b, shows that the oil is absorbed and the oil contact angle (OCA) is about $12^{\circ}$. In this study, as shown in Figure 5c, the WCAs of F1, F2, F3, F4 and F5 were127.0 $\pm 1.2^{\circ}, 130.7 \pm 2.1^{\circ}$, $132.1 \pm 2.6^{\circ}, 133.9 \pm 3.1^{\circ}$, and $138.9 \pm 3.4^{\circ}$, respectively. With a decreasing fiber diameter, the WCA increased slightly. The OCAs of the samples were $16.2 \pm 0.4^{\circ}, 16.0 \pm 0.3^{\circ}, 15.4 \pm 0.3^{\circ}, 15.2 \pm 0.3^{\circ}$, and $12.7 \pm 0.2^{\circ}$, respectively. Figure 5 a shows the image of the WCA of the fiber membrane prepared by a $21 \mathrm{G}$ needle, and Figure $5 \mathrm{~b}$ presents the OCA of the same sample. A similar measurement was done for the absorption time of an oil drop on the porous fiber. The results are shown in Figure 6. One can see that the tendency of absorption time was similar to that of the oil contact angle. The wettability of a solid surface is determined by the chemical nature and roughness of the solid surface. When a large number of hydrophobic groups, such as ester groups, are present on the solid surface, the surface of the material is hydrophobic. If the surface of the substance is hydrophobic, it can be easily changed from hydrophobic to super hydrophobic by increasing the roughness of the substance; thus, the contact angle becomes larger. In this work, since PLA is a hydrophobic polymer, when we decreased the inner diameter of the needle, the water contact angle increased. In addition, it was found that the pore volume also increased significantly. Since the pore volume increased with a decreasing needle diameter, the oil contact angle decreased due to the increasing absorption capacity. 

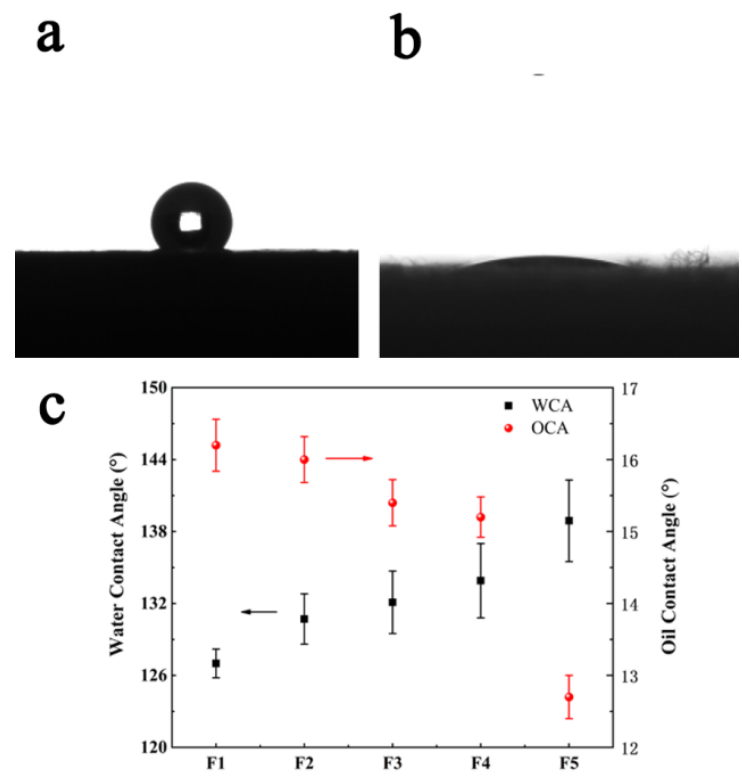

Figure 5. The wettability of fibers is presented: (a) the WCA of fibers prepared by the $21 \mathrm{G}$ needle, (b) the OCA of fibers prepared by $21 \mathrm{G}$ the needle, (c) the WCAs and OCAs of the fiber membranes for samples obtained using different needle diameters.

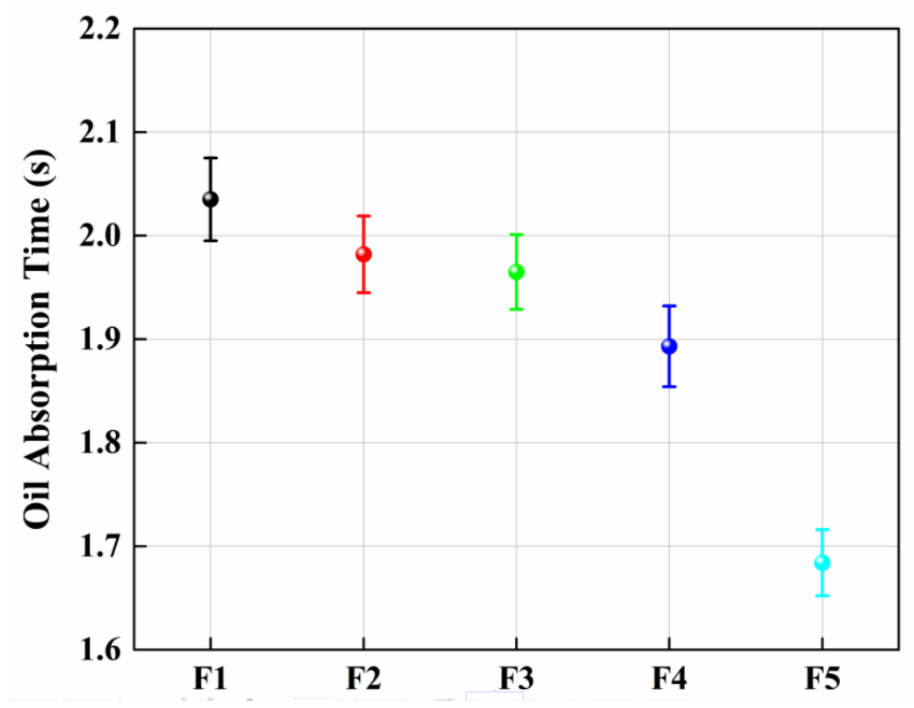

Figure 6. The absorption time of an oil drop on the different porous fibers.

\subsection{ATR-FTIR (Attenuated Total Reflection Flourier Transformed Infrared Spectroscopy)}

It is known that adsorption includes physical adsorption and chemical adsorption. The former is due to the Van der Waals forces between oil/water and the PLA fiber on the fiber surface. The latter depends on the chemical bonds formed between oil/water and the PLA fiber. In order to investigate whether chemical adsorption existed, the PLA membranes were tested by the ATR-FTIR, which is an approach to test the chemical bonds via molecular vibration after the infrared light interacted with the molecules. As shown in Figure 7, the peak at $1757 \mathrm{~cm}^{-1}$ is a stretching vibration mode of carbon-oxygen double bond $(\mathrm{C}=\mathrm{O})$, and the peak at $1183-1088 \mathrm{~cm}^{-1}$ is the stretching vibration mode of carbon-oxygen-carbon ester group (C-O-C) [22-24]. An ester group is a kind of hydrophobic group, which can be combined with the oil molecule and hinders water molecules. This is the reason why PLA is hydrophobic. 


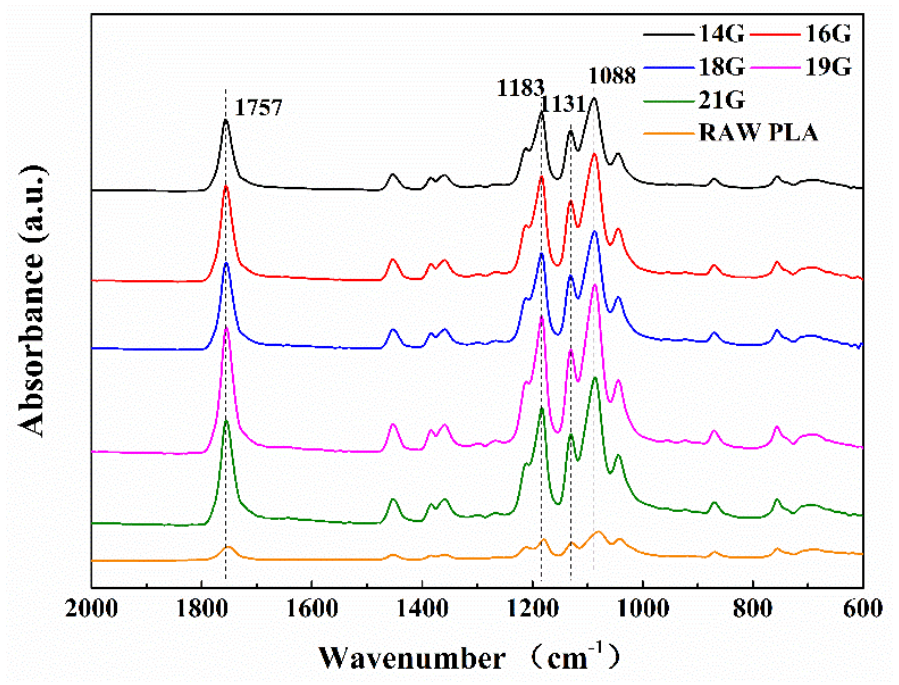

Figure 7. The ATR-FTIR spectra of samples prepared by 14 G, 16 G, 18 G, 19 G, 21 G needles and the raw PLA.

\subsection{Oil Absorption}

We investigated the oil absorption capacity of porous membranes with different diameters for different kinds of oil. These fiber membranes were soaked in vacuum pump oil, peanut oil, and diesel oil, respectively, and compared with the changes in the weight of fiber membrane before and after the absorption. Then, the largest amount of absorption was calculated. As shown in Figure 8, the capacities of absorbed vacuum pump oil for the samples of F1 to F5 were 23.44, 25.44, 32.67, 36.82, and $42.38 \mathrm{~g} / \mathrm{g}$, and those of peanut oil are 21.43, 21.47, 21.63, 25.14, and $28.17 \mathrm{~g} / \mathrm{g}$, respectively. Finally, we also put the same samples in diesel oil for absorption. As a result, these samples presented low absorption capacities, i.e., 5.30, 5.73, 5.68, 6.28, and $6.74 \mathrm{~g} / \mathrm{g}$, respectively. This is because the diameters of the fibers decreased with the decreasing needle size, leading to increased evaporation the of solvent, leaving an increasing specific surface area and also an increasing pore volume; thus, the oil absorption capability on the surface of the fibers increased.

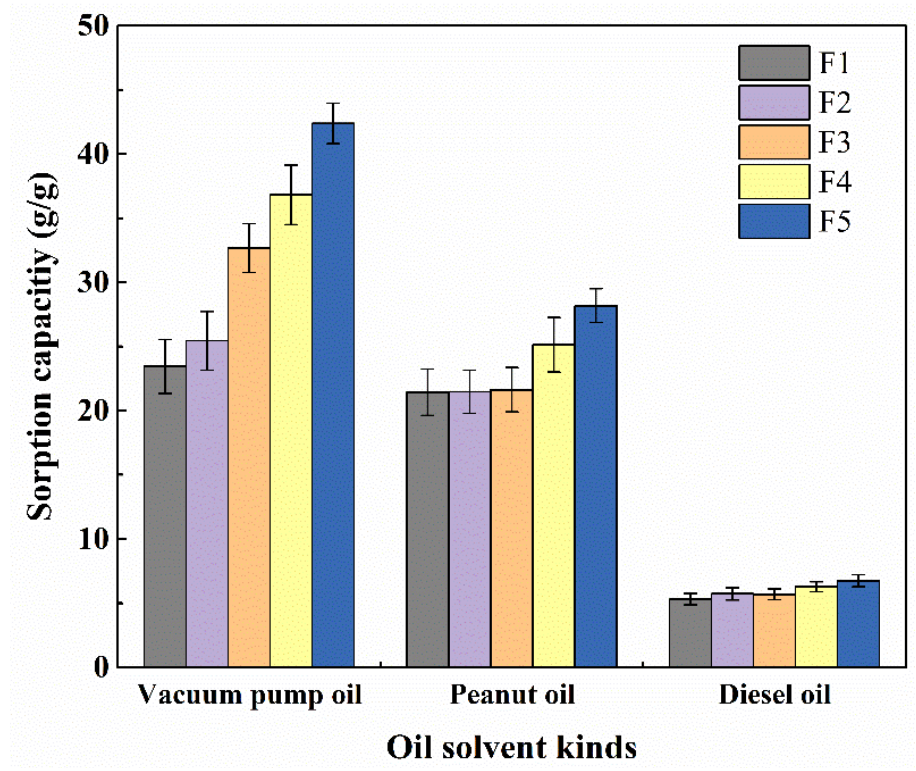

Figure 8. Maximum oil absorption capacity of porous membranes with different diameters for different kinds of oil. 
In Table 1, it is also shown that there were different viscosities for different kinds of oil. Based on the results shown in Figure 8, it seems that the absorption capability is inversely proportional to the viscosity. This is probably because the oil is more likely to adhere to the surface and voids of the fibers to inhibit the oil entering into the interior of the fibers; thus, the oil with lower viscosity has a higher absorption capability [25-28].

Table 1. Viscosity of different types of oil.

\begin{tabular}{cc}
\hline Type & Viscosity/(mPa·s) \\
\hline Vacuum pump oil & 27.20 \\
Peanut oil & 32.40 \\
Diesel oil & 79.10 \\
\hline
\end{tabular}

As one can see, the oil absorption capacity of the fiber membrane increased with the declining diameter of the needle. Therefore, we finally explored whether the fiber membrane could effectively achieve oil absorption from the oil-water suspension. As shown in Figure 9a, in order to absorb the oil, the oil-soluble dye was used to make the oil have a green color. Then, $0.5 \mathrm{~g}$ of the fiber membranes obtained from a $21 \mathrm{G}$ needle were placed in the oil-water suspension, and the absorption capacity was tested and calculated using Equation (1). Figure $9 \mathrm{~b}$ shows an image of the fiber membrane after absorption for $30 \mathrm{~s}$. In addition, the fiber membrane was also able to absorb the vacuum pump oil. As shown in Figure 9c, after $1 \mathrm{~min}$, it was found that there was no significant amount of residual oil [29]. The absorption experiment was further pursued in the pure oil system, showing that the fiber membrane absorbed $10 \mathrm{~g}$ of oil and $0.92 \mathrm{~g}$ of water, respectively, which means that the oil was successfully absorbed from the oil-water suspension.
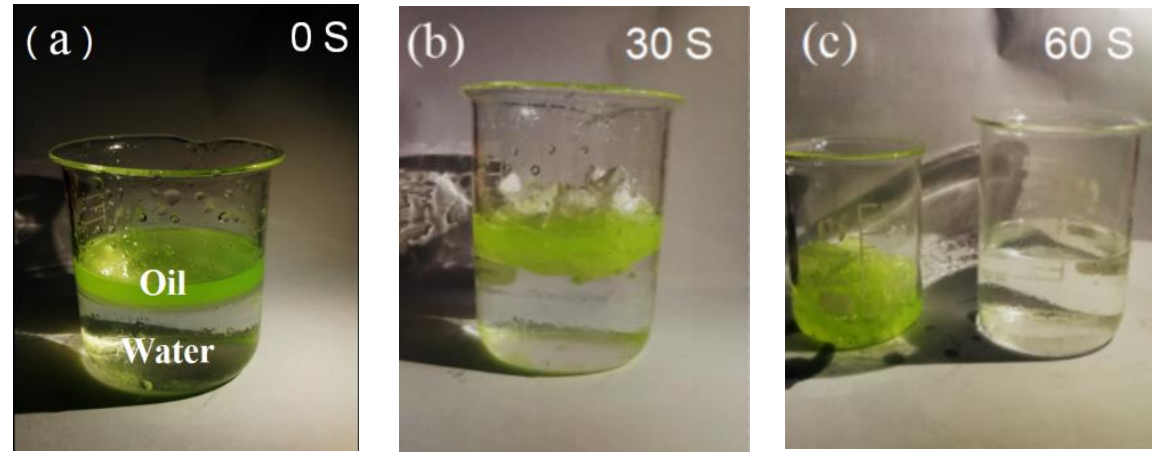

Figure 9. The absorption test was carried out in $60 \mathrm{~s}$. (a) Ten grams of pump oil dyed in green were suspended on the top of $80 \mathrm{~mL}$ water. (b) Fiber membranes of $0.5 \mathrm{~g}$ in weight were fixed to adsorb the oils in the suspension. The images were taken after $30 \mathrm{~s}$. (c) After $60 \mathrm{~s}$, the oil absorption was almost complete, and the adsorbed fiber films were moved to another beaker.

Finally, the approach illustrated above can be scaled up in terms of using rows of syringes to continuously produce large quantities of porous fibers to be applied to clean oil polluted ocean.

\section{Conclusions}

A series of porous PLA fiber membranes with decreasing diameters and pore volumes were successfully prepared by reducing the needle diameter of the syringe. It was observed that the highest absorbed oil capacity was $42.38 \mathrm{~g} / \mathrm{g}$ for vacuum pump oil, $28.17 \mathrm{~g} / \mathrm{g}$ for peanut oil, and $6.74 \mathrm{~g} / \mathrm{g}$ for diesel oil for the oil-water suspensions, respectively, for porous fiber procured using a $21 \mathrm{G}$ needle.

Author Contributions: Conceptualization, S.G.L. and J.W.L.; methodology, J.W.L.; formal analysis, G.P.; investigation, J.W.L., S.C.W. and J.L.W.; writing-original draft preparation, J.W.L. and G.P.; writing-review and editing, S.G.L.; funding acquisition, S.G.L. 
Funding: This research was funded by the National Natural Science Foundation of China, grant number 51372042, 51872053; NSFC-Guangdong Joint Fund, grant number U1501246; and the Guangdong Provincial Natural Science Foundation, grant number 2015A030308004.

Conflicts of Interest: The authors declare no conflict of interest.

\section{References}

1. Short, J.W.; Rice, S.D.; Heintz, R.A.; Carls, M.G.; Moles, A. Long-term effects of crude oil on developing fish: Lessons from the Exxon Valdez oil spill. Energy Sources 2003, 25, 509-517. [CrossRef]

2. Dubansky, B.; Whitehead, A.; Miller, J.T.; Rice, C.D.; Galvez, F. Multitissue molecular, genomic, and developmental effects of the Deepwater Horizon oil spill on resident Gulf killifish (Fundulus grandis). Environ. Sci. Technol. 2013, 47, 5074-5082. [CrossRef]

3. Cortese, B.; Caschera, D.; Federici, F.; Ingo, G.M.; Gigli, G. Superhydrophobic fabrics for oil-water separation through a diamond like carbon (DLC) coating. J. Mater. Chem. A 2014, 2, 6781-6789. [CrossRef]

4. Cortese, B.; Caschera, D.; Padeletti, G.; Ingo, G.M.; Gigli, G. A brief review of surface-functionalized cotton fabrics. Surf. Innov. 2013, 1, 140-156. [CrossRef]

5. Nguyen, D.D.; Tai, N.-H.; Lee, S.-B.; Kuo, W.-S. Superhydrophobic and superoleophilic properties of graphene-based sponges fabricated using a facile dip coating method. Energy Environ. Sci. 2012, 5, 7908-7912. [CrossRef]

6. Li, H.X.; Sun, D.Z.; Tan, W.J.; Fan, S.H.; Wen, X.J.; Qing, G.X.; Li, S.Y.; Deng, W.-Q. Superhydrophobic conjugated microporous polymers for separation and adsorption. Energy Environ. Sci. 2011, 4, 2062-2065. [CrossRef]

7. Ceylan, D.; Dogu, S.; Karacik, B.; Yakan, D.S.; Okay, S.O. Evaluation of butyl rubber as sorbent material for the removal of oil and polycyclic aromatic hydrocarbons from seawater. Environ. Sci. Technol. 2009, 43, 3846-3852. [CrossRef] [PubMed]

8. Acatay, K.; Simsek, E.; Ow-Yang, C.; Menceloglu, Y.Z. Tunable, superhydrophobically stable polymeric surfaces by electrospinning. Angew. Chem. Int. Ed. 2004, 43, 5210-5213. [CrossRef]

9. Miyauchi, Y.; Ding, B.; Shiratori, S. Fabrication of a silver-ragwort-leaf-like super-hydrophobic micro/ nanoporous fibrous mat surface by electrospinning. Nanotechnology 2006, 17, 5151. [CrossRef]

10. Gu, Z.-Z.; Wei, H.-M.; Zhang, R.-Q.; Han, G.-Z.; Pan, C.; Zhang, H.; Tian, X.-J.; Chen, Z.-M. Artificial silver ragwort surface. Appl. Phys. Lett. 2005, 86, 201915. [CrossRef]

11. Rojas, J.; Montero, G.A.; Habibi, Y. Electrospun nanocomposites from polystyrene loaded with cellulose nanowhiskers. J. Appl. Polym. Sci. 2009, 113, 927-935. [CrossRef]

12. Ma, M.; Hill, R.M.; Lowery, J.L.; Fridrikh, S.V.; Rutledge, G.C. Electrospun Poly(Styrene-blockdimethylsiloxane) Block Copolymer Fibers Exhibiting Superhydrophobicity. Langmuir 2005, 21, 5549-5554. [CrossRef]

13. Wang, S.; Li, Y.; Fei, X.; Sun, M.; Zhang, C.; Li, Y.; Yang, Q.; Hong, X. Preparation of a durable superhydrophobic membrane by electrospinning poly (vinylidene fluoride) (PVDF) mixed with epoxy-siloxane modified $\mathrm{SiO}_{2}$ nanoparticles: A possible route to superhydrophobic surfaces with low water sliding angle and high water contact angle. J. Colloid Interface Sci. 2011, 359, 380-388.

14. Schroeter, M.; Wildemann, B.; Lendlein, A. Ch. 20, Biodegradable Materials. In Regenerative Medicine: From Protocol to Patient; Steinhoff, G., Ed.; Springer Science+Business Media B.V.: Berlin/Heidelberg, Germany, 2011; pp. 469-492.

15. Sawalha, H.; Schroen, K.; Boom, R. Biodegradable polymeric microcapsules: Preparation and properties. Chem. Eng. J. 2011, 169, 1-10. [CrossRef]

16. Yue, M.; Zhou, B.; Jiao, K.; Qian, X.; Xu, Z.; Teng, K.; Zhao, L.; Wang, J.; Jiao, Y. Switchable hydrophobic/ hydrophilic surface of electrospun poly(L-lactide) membranes obtained by CF4microwave plasma treatment. Appl. Surf. Sci. 2015, 327, 93-99. [CrossRef]

17. Xu, J.; Zhang, J.; Gao, W.; Liang, H.; Wang, H.; Li, J. Preparation of chitosan/PLA blend micro/nanofibers by electrospinning. Mater. Lett. 2009, 63, 658-660. [CrossRef]

18. Lu, L.; Wu, D.; Zhang, M.; Zhou, W. Fabrication of polylactide/poly (ecaprolactone) blend fibers by electrospinning: Morphology and orientation. Ind. Eng. Chem. Res. 2012, 51, 3682-3691. [CrossRef] 
19. Salem, D. Electrospinning of nanofibers and the charge injection method. In Nanofibers and Nanotechnology in Textiles; Brown, P.J., Stevens, K., Eds.; Woodhead Publishing: Cambridge, UK, 2007; pp. 3-21.

20. Wu, J.; Wang, N.; Wang, L.; Dong, H.; Zhao, Y.; Jiang, L. Electrospun porous structure fibrous film with high oil adsorption capacity. ACS Appl. Mater. Interfaces 2012, 4, 3207-3212. [CrossRef]

21. Zahid, M.A.; Halligan, J.E.; Johnson, R.F. Oil Slick Removal Using Matrices of Polypropylene Filaments. Ind. Eng. Chem. Process Des. Dev. 1972, 11, 550-555. [CrossRef]

22. Popelka, S.; Machova, L.; Rypacek, F. Adsorption of poly (ethylene oxide)-block-polylactide copolymers on polylactide as studied by ATR-FTIR spectroscopy. J. Colloid Interface Sci. 2007, 308, 291-299. [CrossRef]

23. Agarwal, M.; Koelling, K.W.; Chalmers, J.J. Characterization of the Degradation of Polylactic Acid Polymer in a solid substrate environment. Biotechnol. Prog. 1998, 14, 517-526. [CrossRef]

24. Yang, S.-L.; Wu, Z.-H.; Yang, W.; Yang, M.-B. Thermal and mechanical properties of chemical crosslinked polylactide (PLA). Polym. Test. 2008, 27, 957-963. [CrossRef]

25. Qiao, Y.; Zhao, L.L.; Li, P.; Sun, H.X.; Li, S. Electrospun polystyrene/polyacrylonitrile fiber with high oil sorption capacity. J. Reinf. Plast. Compd. 2014, 33, 1849-1858. [CrossRef]

26. Johnson, R.F.; Manjrekar, T.G.; Halligan, J.E. Removal of oil from water surfaces by sorption on unstructured fibers. Environ. Sci. Technol. 1973, 7, 439-443. [CrossRef]

27. Zhu, H.T.; Qiu, S.S.; Jiang, W.; Wu, D.X.; Zhang, C.Y. Evaluation of electrospun polyvinyl chloride/ polystyrene fibers as sorbent materials for oil spill cleanup. Environ. Sci. Technol. 2011, 45, 4527-4531. [CrossRef]

28. Tadmor, R.; Das, R.; Gulec, S.; Liu, J.; N'guessan, H.E.; Shah, M.; Wasnik, P.S.; Yadav, S.B. Solid-Liquid Work of Adhesion. Langmuir 2017, 33, 3594-3600. [CrossRef]

29. Tadmor, R.; Pepper, K.G. Interfacial tension and spreading coefficient for thin films. Langmuir 2008, 24, 3185-3190. [CrossRef]

(C) 2019 by the authors. Licensee MDPI, Basel, Switzerland. This article is an open access article distributed under the terms and conditions of the Creative Commons Attribution (CC BY) license (http:/ / creativecommons.org/licenses/by/4.0/). 